\title{
Farm work injuries among a cohort of children in Kentucky, USA
}

\author{
Steven R. Browning ${ }^{1}$, Susan C. Westneat ${ }^{2}$, Deborah B. Reed ${ }^{2}$ \\ ${ }^{1}$ Department of Epidemiology, College of Public Health, University of Kentucky, Lexington, Kentucky, USA \\ ${ }^{2}$ College of Nursing, University of Kentucky, Lexington, Kentucky, USA \\ Browning SR, Westneat SC, Reed DB. Farm work injuries among a cohort of children in Kentucky, USA. Ann Agric Environ Med. 2016; 23(4): \\ 604-611. doi: 10.5604/12321966.1226854
}

\section{Abstract}

Children residing on farms with livestock may be at an increased risk for work-related injuries, compared to children who work on other commodity farms. This study characterizes children's work tasks on Kentucky farms and assesses whether children who work on beef cattle farms are at an increased risk for farm work injuries. The results of a cohort study of children aged 5-18 years ( $\mathrm{N}=999$ at baseline) working on family farms in Kentucky, followed for two consecutive years after an initial enumeration five years previously, found that $70 \%$ of the children were involved in animal-related chores. Across all age groups, children on beef cattle farms devoted a greater number of hours per week to farm work, compared to children living on other commodity farms, especially during the school year. For all children in the study, working more than 180 days per year, performing farm work independently, and working on a beef cattle farm (compared to other commodity farm), increased the risk of a farm work injury. However, none of these associations were statistically significant. For male children only, the performance of work tasks independently was significantly associated with a 2.4-fold increased risk (OR $=2.41 ; 95 \% \mathrm{Cl}$ : 1.15-5.06; $\mathrm{P}=0.02$ ) for a farm work injury, after controlling for days of working, age, period of data collection, and commodity type of the farm.

\section{Key words}

injury, children, farming, agriculture

\section{INTRODUCTION}

Epidemiologic studies of risk factors for childhood agricultural injuries have documented the hazards associated with farm machinery (tractors, augers, power take-offs), farm animals (especially cattle and horses), falls from structures, and injuries from other equipment and tools [1-7]. Several studies have demonstrated that farm animals and livestock are important sources of injury among farm workers, particularly adults $[6,8-14]$. Less attention has been given to examining the hazards to children who work on specific commodity farms and examining the task assignments, work hours, and farm injuries in animal-intensive operations.

Studies undertaken on adults working on farms with beef or dairy cattle have documented increased farm injury rates in comparison to farms without animals [12, 15-18]. Nordstrom et al. reported animals as the most frequent source of injury within their population-based, prospective study of farm-related injuries [15]. They found the injury risk to be 2.5 times greater among dairy farm residents than non-dairy farm residents. In Vermont, livestock accounted for $38 \%$ of all injuries among dairy cattle farmers [17]. Boyle et al. (1996) described results from a case-control study of farm household members who sustained animal-related injuries resulting from dairy cattle activities. Milking had the greatest risk for injury, with odds ratios increasing with hours per week devoted to milking; trimming or treating of hooves was also associated with an increased risk for injury $(\mathrm{OR}=4.2$; 95\% CI: 1.2-15.4) [19].

Address for correspondence: Steven R. Browning, Department of Epidemiology, College of Public Health, University of Kentucky, Suite 209B, 111 Washington Avenue, Lexington, Kentucky 40536-0003, USA

E-mail: srbrown@uky.edu.

Received: 02August 2016; accepted: 27 September 2016
Layde et al. [16] investigated animal-related injuries as part of a population-based, case-control study of injuries in farm residents in central Wisconsin, and documented how farm management practices may reduce the risk of injuries. The use of all-terrain vehicles (ATVs) for chores $(\mathrm{OR}=0.47)$ and feeding cows in a barn in the summer $(\mathrm{OR}=0.39)$, rather than sending them to the pasture, were activities found to reduce the risk of an animal-related injury More recent research has focused on the use of management-intensive grazing (MIG), which decreases the reliance on the use of tractors and other machinery, and may influence the exposure of children to hazards on farms where cattle and other animals are primary commodities [20].

The issue of the role of adult supervision was explored among 344 paediatric cases of farm work injury by Morrongiello et al. [21]. While two-thirds of the child injury cases had an adult supervisor who was available, and approximately half of the injury events had an adult in close proximity, the supervision of children working on farms was not often continuous. Agreement about what constitutes adequate supervision of children working on farms or appropriate assignment to tasks, especially related to work with large animals, farm tractors, and all-terrain vehicles, has been an area of continuing debate among researchers [20, 22, 23].

In Kentucky, our baseline cross-sectional study documented that animal care chores were one of the principal tasks engaged in by children of all ages and both genders living on farms [24]. To extend data collection on this established cohort of children, with a focus on children's chores in beef cattle operations, two consecutive annual surveys were conducted of children living and working on family farms in Kentucky. The primary aims of the study were to characterize the work tasks and exposures of children, and to examine factors in a longitudinal fashion, such as 
level of work effort and supervision, in association with risk of a farm work injury.

\section{MATERIALS AND METHOD}

A study was conducted of a fixed cohort of children aged 5 18 years, who were first enumerated at baseline (1994-1995) as part of the Kentucky Farm Family Health and Hazard Surveillance Project. Children aged 5-18 years, living on family-owned and operated farms in Kentucky constituted the target population. The design consisted of two telephone surveys; the first was conducted from June-August 2000 and the second undertaken from July-August 2001. The children for these two follow-up surveys were drawn from participants in the original Farm Family Health and Hazard Surveillance Project. A 'farm' was defined as any establishment from which $\$ 1,000$ or more of agricultural products from livestock, crop, or specialty operations were sold or would normally be sold during a year [25]. Details regarding the sampling and methods used for the baseline survey are discussed in detail elsewhere [24].

From the sample of 999 children interviewed at baseline, children who met the following eligibility criteria were selected for the follow-up surveys: 1) children between the ages of 5 - 18 years at first follow-up (June 2000); 2) children still living on the same farm as at the time of the baseline survey in 1994-1995; and 3) the parent or guardian agreed to be re-interviewed for the follow-up surveys. The study sample was selected from the cohort of 999 children ages 1 - 18 years who were first interviewed in 1994-1995 as part of the Kentucky Farm Family Health and Hazard Surveillance Project [24]. The baseline cohort included children living on a geographically-dispersed sample of family-owned and operated farms throughout the State. Previous research by Browning et al. (2003) indicated that the farms in the sample for this study were generally comparable to the farms in the state, based on a comparison with Census of Agriculture data $[24,25]$.

The initial contact of children for the study was undertaken by mail with receipt of a packet of materials containing an introductory letter describing the study, a descriptive brochure on key findings from the baseline study, and a certificate of appreciation in the name of the child. The letter was addressed to the parent or guardian of the child at the address of the farm household from the baseline interview, and reminded the participants of their involvement in the 1994-1995 baseline study. Following the initial letter, study subjects were contacted and consent for continued participation was obtained by phone. A telephone survey was undertaken in 2000 (first follow-up) and a subsequent survey in 2001 (second follow-up). The telephone interview procedures for the cohort study followed those established for the baseline survey, as documented elsewhere [24]. Data were collected at the Survey Research Center at the University of Kentucky using a computer-assisted telephone interviewing (CATI) system. Telephone interview scripts were checked and skip patterns were tested prior to activation of the telephone survey. Telephone interviewers were trained in the administration of the survey, with emphasis placed on their understanding of the agricultural terms used in the instrument, and periodically monitored by Survey Research Center personnel for their completeness of the interviews, courtesy and comportment, administration, and other quality control measures.

Interviewers from the Survey Research Center at the University of Kentucky called participants for scheduling the telephone interview and made every effort to accommodate respondent schedules. Respondents were assured during the interview of the confidentiality of their responses. An effort was made to preserve the format and content of most questions given in the baseline survey in order to facilitate comparison of responses over time. Demographic questions were reassessed at first follow-up and second follow-up for validation purposes. The questionnaire took approximately 20 minutes to administer.

The questionnaires for the follow-up surveys were designed to obtain data on child characteristics (anthropometric, behavioural, and family role variables), participation in selected farm tasks and hours at tasks (with detailed questions for beef cattle farms), parental influences (including prohibitions, supervision, and experience), and injuries to children in the past year. Standardized questions for demographic variables and for assessment of the occurrence of injury came from the National Health Interview Survey and those used in the previous studies of farm-related injuries [24]. The study was approved by the Institutional Review Board of the University of Kentucky.

Data for the telephone interview components of the study were entered directly using the CATI system at the Survey Research Center. For the purposes of this research, farm work injuries were defined as injuries that 1) occurred while performing farm work or farm chores, and 2) required medical attention or treatment, or interfered with work or school activities. An event was defined as a report of at least one farm work, non-fatal injury in the previous year, or since the last survey was administered.This definition extended to farm work injuries that occurred in off-farm locations, such as in the woods or on another person's farm. Categories for the classification of the external cause of the injury were developed based on categorical definitions used in previous research [24]. The status of the farm operation was reassessed at first follow-up for verification of the classification of farm type and the types of livestock kept or sold on the farm as part of its normal commercial operations.

Descriptive statistics, including means, frequencies, percentages, and rates, were calculated to examine the distribution of injuries and potential risk factors in the cohort. The relationship between farm work injury and potential risk factors was assessed using a logistic regression model fitted by the generalized estimating equations (GEE) method to account for the non-independence of repeated measures on the same subjects. This longitudinal logistic approach was undertaken due to a lack of exact injury times, and the potential for repeat injuries across the several time periods of data collection [27]. Data management and analysis were performed using SAS 9.3 [26].

The model for the farm injuries was based on defining farm work injuries as a binary variable, based on the study injury definition that the injury occurred in the past year as a result of performing farm work or chores. The following variables were included in the longitudinal analysis: 1) commodity of the farm (beef cattle farm vs. other), 2) gender of the child (male, female), 3) age of the child at the time of injury, 4) number of days the child performed farm work in the past 12 months (greater than or equal to 180 days vs. less than 
180 days), 5) supervision of farm work (performs farm work independently vs. supervised or assists), and 6) the time of the survey (baseline, follow-up 1, follow-up 2). In this model, gender remains a stable variable, while all the other variables are time-dependent covariates, with the values changing across the time periods in the cohort study. The variable for beef cattle farm was defined as whether the farm currently had beef cattle (at the time of the survey) for the first and second follow-up surveys; the variable was defined on the basis of the respondent's classification of the type of farm (tobacco, beef cattle, dairy, cash-grain, etc.) in the baseline survey. Analyses were performed using observations with complete data on all factors presently under consideration. Adjusted odds ratios and 95\% confidence intervals (CI) were estimated for each factor, including demographic characteristics, days of farm work, and level of supervision on the risk of a farm work injury.

\section{RESULTS}

Demographics of the cohort. The distributions of participant demographic characteristics across the three time periods of data collection are given in Table 1. The eligible sample frame for the cohort follow-up used in 2000 was composed of 477 persons, $48 \%$ of the baseline cohort from 1994-1995. Follow-up of the eligible children, through parental proxy, at the first survey yielded a $63 \%$ response rate, with followup at the second survey in 2001 at $81 \%$. At baseline, 53\% of the cohort was male. For the first follow-up, $48 \%$ of the study population was male and at second follow-up, $51 \%$ of the cohort was male, suggesting no participation bias in the follow-up with respect to gender.

In the 2001 survey, an estimated $72 \%$ of the farm households reported a gross household income in excess of $\$ 30,000$ per year, compared with $65 \%$ at the baseline survey, indicating a modest tendency for the higher income farms to continue participation across time. Overall, the majority of the telephone interviews were conducted with the mothers of the target child (89\% at baseline; $86 \%$ at the final follow-up). The participation of parents with children who were actively engaged in doing farm work in the past 12 months increased across calendar time, also reflecting the aging of the cohort, as older children were more likely to engage in farm work. Roughly one-quarter of the children were independently involved in performing farm work at the first and second follow-up surveys.

Exposure profile. Estimates of the age and gender participation in specific farm tasks, especially those related to animal care, at the first follow-up survey are given in Table 2. In general, less than one-fourth of the children aged 5-9 years participated in tasks related to the care and feeding of cattle. The rates of participation in cattle-related chores generally increased with the age of the children, with the participation rates of boys generally twice the rates for girls for a diverse set of cattle related chores. Boys aged 15-18 had the highest rates of participation in cattle-related chores, especially assisting with the loading of cattle (79\%), lifting hay bales for feeding (72\%), assisting in treating cattle with medications (66\%), and feeding cattle using a tractor (59\%). In addition, it is notable that this age group of boys engaged in a number of tasks in which they had very direct animal contact,
Table 1. Demographics distributions of children in the cohort by time period

\begin{tabular}{ccccccccc}
\hline & \multicolumn{1}{c}{$\begin{array}{c}\text { Baseline } \\
94-95\end{array}$} & \multicolumn{7}{c}{ Age 5-18 Cohort } \\
\hline & \multicolumn{9}{c}{$\begin{array}{c}\text { Eligible } \\
\text { Sample }\end{array}$} & Survey 2000 & \multicolumn{2}{c}{ Survey 2001 } \\
\hline & & $(\mathrm{N}=999)$ & $(\mathrm{N}=477)$ & $(\mathrm{N}=299)$ & \multicolumn{2}{c}{$(\mathrm{N}=242)$} \\
\hline Demographic & $\mathrm{N}$ & $\%$ & $\mathrm{~N}$ & $\%$ & $\mathrm{~N}$ & $\%$ & $\mathrm{~N}$ & $\%$ \\
\hline Gender/Age & & & & & & & & \\
\hline Male & & & & & & & & \\
\hline $0-4$ & 60 & 11.3 & - & - & - & - & - & - \\
\hline $5-9$ & 102 & 19.2 & 60 & 25.3 & 39 & 26.9 & 26 & 21.1 \\
\hline $10-14$ & 151 & 28.4 & 102 & 43.0 & 62 & 42.8 & 55 & 44.7 \\
\hline $15-18$ & 219 & 41.2 & 75 & 31.7 & 44 & 30.3 & 42 & 34.2 \\
\hline Total & 532 & & 237 & & 145 & & 123 & \\
\hline Female & & & & & & & & \\
\hline $0-4$ & 60 & 12.8 & - & - & - & - & - & - \\
\hline $5-9$ & 98 & 21.0 & 60 & 25.0 & 35 & 22.7 & 22 & 18.5 \\
\hline $10-14$ & 150 & 32.1 & 98 & 40.8 & 65 & 42.2 & 59 & 49.6 \\
\hline $15-18$ & 159 & 34.0 & 82 & 34.2 & 54 & 35.1 & 38 & 31.9 \\
\hline Total & 467 & & 240 & & 154 & & 119 \\
\hline
\end{tabular}

Gross household income

\begin{tabular}{lcccccccc}
\hline$<20,000$ & 76 & 7.6 & 37 & 7.8 & 15 & 5.0 & 13 & 5.4 \\
\hline $20,000-30,000$ & 166 & 16.7 & 73 & 15.3 & 29 & 9.7 & 35 & 14.5 \\
\hline $30,000-50,000$ & 316 & 31.6 & 154 & 32.3 & 86 & 28.8 & 94 & 38.8 \\
\hline$>50,000$ & 335 & 33.5 & 159 & 33.3 & 132 & 44.2 & 81 & 33.5 \\
\hline $\begin{array}{l}\text { Refused/Don't } \\
\text { know }\end{array}$ & 106 & 10.6 & 54 & 11.3 & 37 & 12.3 & 19 & 7.9 \\
\hline
\end{tabular}

\section{Relationship to child}

\begin{tabular}{lcccccccc}
\hline Mother & 886 & 88.7 & 421 & 88.3 & 237 & 79.3 & 208 & 86.0 \\
\hline Father & 63 & 6.3 & 30 & 6.3 & 53 & 17.7 & 25 & 10.3 \\
\hline $\begin{array}{l}\text { Guardian/ } \\
\text { other }\end{array}$ & 50 & 5.0 & 26 & 5.5 & 9 & 3.0 & 9 & 3.7 \\
\hline Farm type & & & & & & & & \\
\hline Beef & 407 & 40.7 & 203 & 42.6 & 87 & 29.1 & 106 & 43.8 \\
\hline Other & 592 & 59.3 & 274 & 57.4 & 212 & 70.9 & 136 & 56.2 \\
\hline
\end{tabular}

\section{Child did farm work in past 12 months}

\begin{tabular}{lllllllll}
\hline Yes & 786 & 78.7 & 301 & 63.1 & 268 & 89.6 & 206 & 85.1 \\
\hline No & 213 & 21.3 & 176 & 36.9 & 31 & 10.4 & 36 & 14.9 \\
\hline
\end{tabular}

Number days farm work in past 12 months ${ }^{1}$

\begin{tabular}{lcccccccc}
\hline Few & 370 & 47.0 & 174 & 57.8 & 159 & 59.3 & 118 & 57.3 \\
\hline Half & 125 & 16.0 & 40 & 13.3 & 41 & 15.3 & 24 & 11.7 \\
\hline Most & 291 & 37.0 & 87 & 28.9 & 68 & 25.4 & 64 & 31.1
\end{tabular}

Number of children per household

\begin{tabular}{ccccccccc}
\hline 1 & 823 & 82.4 & 333 & 69.8 & 233 & 78.0 & 179 & 74.0 \\
\hline$>1$ & 176 & 17.6 & 144 & 30.2 & 66 & 22.0 & 63 & 26.0 \\
\hline
\end{tabular}

\section{Child involvement in farm work ${ }^{2}$}

\begin{tabular}{lcccccccc}
\hline Assist/watch & 568 & 61.4 & 323 & 80.3 & 94 & 35.2 & 68 & 33.0 \\
\hline Supervised & 231 & 25.4 & 65 & 16.2 & 108 & 40.4 & 90 & 43.7 \\
\hline Independent & 120 & 13.2 & 14 & 3.5 & 65 & 24.4 & 48 & 23.3 \\
\hline
\end{tabular}

Number of days of farm work is given only for children doing farm work in past 12 months. ${ }^{2}$ Child involvement in farm work is only reported for children doing farm work or for which parent/ guardian indicated that the assisted or watched; children with no involvement in farm work are not include in the column percentage for this variable. 
Table 2. Prevalence estimates for participation in specific farm tasks by age and gender for the first follow-up survey ( $\mathrm{N}=177$ children; all farms)

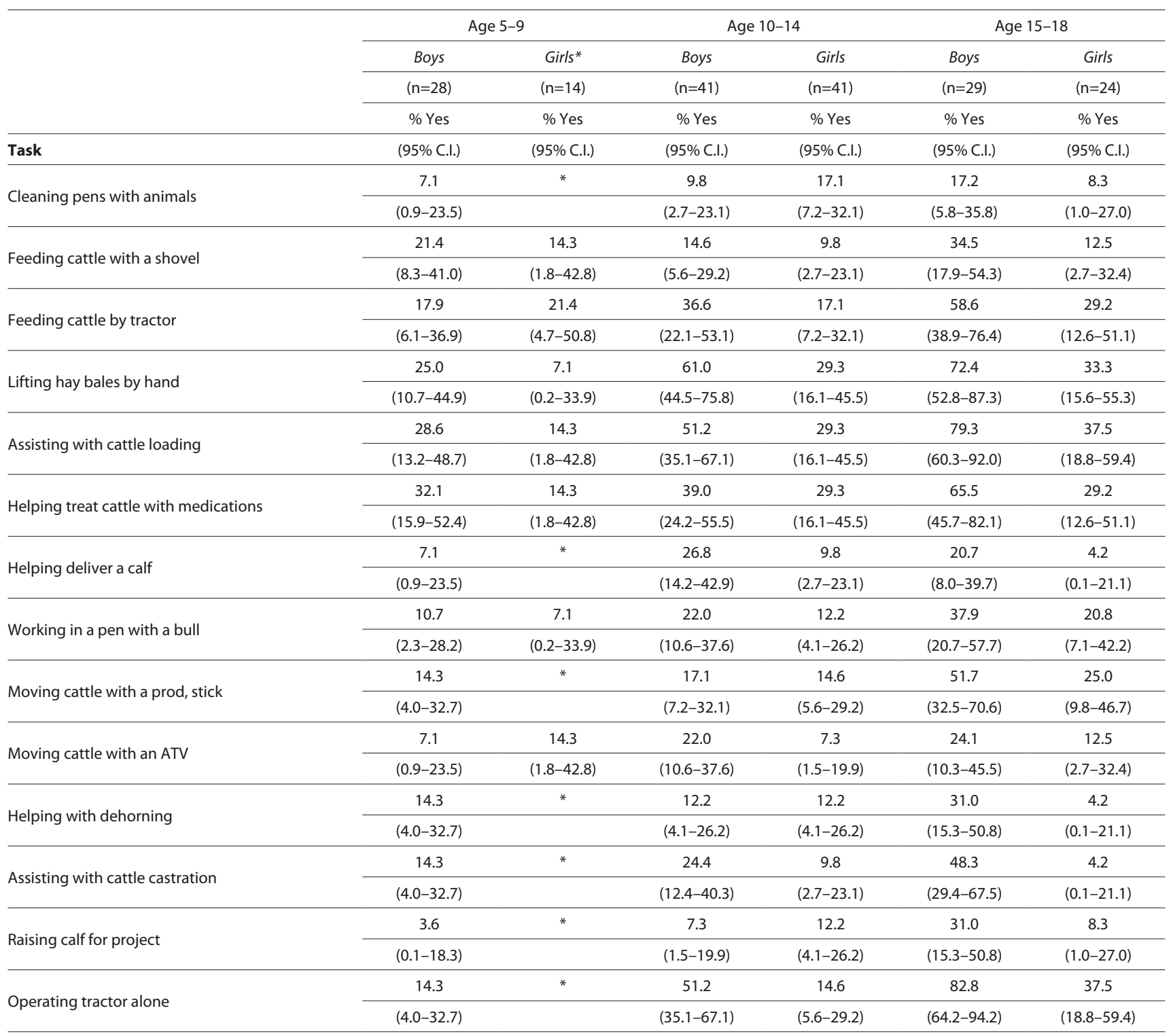

Analysis is based on 177 children of the 268 who performed farm work or farm chores in the past 12 months, and provided complete answers to the questions regarding participation in farm tasks. * Insufficient data to calculate a stable prevalence estimate and confidence interval.

including assistance in cattle castration (48\%), working in the yard with a bull (38\%), help with dehorning (31\%), and assisting in the delivery of a calf (21\%). For the majority of cattle related tasks, less than one-third of girls aged 15-18 years were reported to have participated in these tasks.

Based on estimates from the 2001 survey, children (all ages/ gender) residing on farms which currently had beef cattle, averaged 6.2 hours $(\mathrm{SE}=0.47)$ work during the school year (September -May) in comparison to children working on other commodity farms who averaged 4.6 hours $(\mathrm{SE}=0.51$ ) per week. During the school year, the most marked commodity difference in hours worked per week was for boys aged 15 - 18, in which those residing on beef farms worked 10.3 hours per week ( $\mathrm{SE}=0.98)$, in comparison to 5.2 hours per week $(\mathrm{SE}=1.6)$ for those on other commodity farms. On beef cattle farms, boys 15-18 years of age worked an average of 19.5 hours per week $(\mathrm{SE}=1.7)$ during the summer months, with work hours ranging from 1-42 hours. With respect to work hours, boys aged 15-18 on beef cattle farms work nearly twice as many hours in the summer (19.5 hours) than girls of comparable age (10.0 hours per week in the summer for girls aged $15-18$ years).

Farm work injury analysis. There were 46 farm work injuries reported in the cohort of children during the time period of the study (Tab. 3). The leading external cause of reported injury (37\%) was contact with a foreign object (e.g., injuries to the eyes from rocks, sticks, or hay, and injuries to the extremities from hand tools and barbed wire). Machineryrelated injuries (fractures and contusions from ATV and tractor crashes, and cuts from using hitching equipment and hand tools) were the second most frequent (24\%). The upper extremities (arms and hands) were the body parts most commonly injured during farm work. Cuts constituted 37\% of the reported injuries. The season of injury was available only for the baseline survey $(\mathrm{N}=29)$; most of those reported injuries (57\%) occurred during the summer. The distribution of injuries was relatively evenly divided between the beef 
Table 3. Distribution of farm work injuries $(n=46)$ for children in the cohort by injury characteristics

\begin{tabular}{lccc}
\hline Characteristic & $\begin{array}{c}\text { No. of injured } \\
\text { children }\end{array}$ & Percentage & $95 \%$ C.I. \\
\hline External cause: & 17 & 37.0 & $23.6-52.5$ \\
\hline Object & 11 & 23.9 & $13.1-39.1$ \\
\hline Machine & 4 & 8.7 & $2.8-21.7$ \\
\hline Animal & 4 & 8.7 & $2.8-21.7$ \\
\hline Falls from height & 3 & 6.5 & $1.7-18.9$ \\
\hline Lifting & 1 & 2.2 & $0.1-13.0$ \\
\hline Motor vehicle & 6 & 13.0 & $5.4-27.0$ \\
\hline Other ${ }^{2}$ & 16 & 34.8 & \\
\hline Part of body injured: & 13 & 28.2 & $16.8-50.3$ \\
\hline Upper extremities & 5 & 10.9 & $4.1-24.4$ \\
\hline Lower extremities & 5 & 10.9 & $4.1-24.4$ \\
\hline Torso & 2 & 4.3 & $0.8-16.0$ \\
\hline Head/neck & 5 & 10.9 & $4.1-24.4$ \\
\hline Multiple body parts & & & \\
\hline Not specified & 17 & 37.0 & $23.6-52.5$ \\
\hline Type of injury: & 5 & 10.9 & $4.1-24.4$ \\
\hline Cut & 4 & 8.7 & $2.8-21.7$ \\
\hline Contusion & 2 & 4.3 & $0.8-16.0$ \\
\hline Strain & 3 & 6.5 & $1.7-18.9$ \\
\hline Multiple & 14 & 30.4 & $0.1-13.0$ \\
\hline Fracture & & & $18.2-45.9$ \\
\hline Amputation & & & \\
\hline Other ${ }^{3}$ & & & \\
\hline Seaso inury ocur & & & \\
\hline
\end{tabular}

\begin{tabular}{lccc}
\hline Season injury occurred: & & & \\
\hline Spring & 8 & 28.6 & $14.3-53.8$ \\
\hline Summer & 16 & 57.1 & $33.3-73.1$ \\
\hline Fall & 3 & 10.7 & $-^{1}$ \\
\hline Winter & 1 & 3.6 & $-^{1}$
\end{tabular}

Farm type:

\begin{tabular}{llll}
\hline Beef cattle & 21 & 45.7 & $31.2-60.8$ \\
\hline Other & 25 & 54.3 & $39.2-68.8$ \\
\hline
\end{tabular}

\begin{tabular}{lccc}
\hline Place injury occurred: & & & \\
\hline Parental farm & 40 & 87.0 & $73.1-94.6$ \\
\hline Other farm $^{4}$ & 6 & 13.0 & $5.4-27.0$
\end{tabular}

Consulted medical professional after injury:

\begin{tabular}{llll}
\hline Yes & 34 & 73.9 & $58.6-85.2$ \\
\hline No & 12 & 26.1 & $14.8-41.4$ \\
\hline Missed $>4$ hours of work: & & & \\
\hline Yes & 21 & 45.7 & $31.2-60.8$ \\
\hline No & 25 & 54.3 & $39.2-68.8$ \\
\hline Adult present at time of injury: & & & \\
\hline Yes & 32 & 69.6 & $54.1-81.8$ \\
\hline No & 14 & 30.4 & $18.5-44.8$ \\
\hline
\end{tabular}

${ }^{1}$ Insufficient data to calculate an interval.

${ }^{2}$ Includes injuries from animal feeding chores (e.g. milking), welding, and a firearm injury.

${ }^{3}$ Includes dislocations, scrapes, stabs, toxic effects, and other multiple injuries.

${ }^{3}$ Includes dislocations, scrapes, stabs, toxic effe
${ }^{4}$ Includes a neighbour's/relative's farm or field.

${ }^{5}$ Season of injury was only assessed at the baseline survey for the 28 cases.

cattle farms and the other types of farms in the study. A medical professional was consulted for $74 \%$ of the injuries reported in the study, and slightly under half of the children missed more than four hours of work or school as a result of the injury.

Rates of farm work injuries by select demographic characteristics are given in Table 4 . The crude farm work injury rate for male children in the cohort was 5.1 injured children per 100 children per year, and accounted for $84 \%$ of the injury events reported in the study. Farm work injury rates were highest in the oldest age group of children (4.6 injured/100), for those who worked half or more days per year (5.9/100), and for children who performed most of their farm tasks independently (6.9/100). Statistically significant differences in these rates were evident for gender and the performance of farm tasks independently in the crude analysis.

Longitudinal analysis. The longitudinal analysis of farm work injuries across the three periods of data collection

Table 4. Distribution of children in the cohort with farm work injuries and farm work injury rates

\begin{tabular}{lccc}
\hline Characteristic & $\begin{array}{c}\text { No. of farm } \\
\text { work injuries'. } \\
(\mathrm{N}=46)\end{array}$ & $\begin{array}{c}\text { Farm work } \\
\text { injury rate }{ }^{2}\end{array}$ & $95 \%$ C.I. \\
\hline Gender: & 39 & 5.1 & $3.7-7.0$ \\
\hline Male & 7 & 1.0 & $0.4-2.1$ \\
\hline Female & & & \\
\hline Age: & 20 & 4.6 & $2.8-7.1$ \\
\hline $16-18$ & 19 & 2.8 & $1.7-4.4$ \\
\hline $10-15$ & 7 & 2.1 & $0.8-4.3$ \\
\hline $5-9$ & & &
\end{tabular}

Farm work in past 12 months (days):

\begin{tabular}{llll}
\hline Half or more days $(>=180)$ & 29 & 5.9 & $4.0-8.3$ \\
\hline Less than half days $(<180)$ & 17 & 2.7 & $1.6-4.4$
\end{tabular}

Level of involvement in farm work:

\begin{tabular}{llll}
\hline Performing tasks independently & 14 & 6.9 & $4.0-10.9$ \\
\hline
\end{tabular}

\begin{tabular}{llll}
\hline Working under supervision or assisting & 32 & 2.7 & $1.8-3.9$ \\
\hline
\end{tabular}

Type of farm:

\begin{tabular}{llll}
\hline Beef cattle & 21 & 3.9 & $2.5-6.0$ \\
\hline Other commodity & 25 & 4.4 & $2.9-6.5$ \\
\hline
\end{tabular}

\section{Time period:}

\begin{tabular}{lccc}
\hline Follow-up (2001) & 6 & 2.5 & $0.9-5.3$ \\
\hline Follow-up (2000) & 11 & 3.7 & $1.9-6.6$ \\
\hline Baseline & 29 & 3.2 & $2.1-4.6$
\end{tabular}

Baseline

$\begin{array}{lll}29 & 3.2 & 2.1-4.6\end{array}$

${ }^{1}$ Farm work injurieswere defined as proxy reported injuries occurring in children in the 12 months before the interview, that occurred on the farm as a result of performing farm work or farm chores. Analysis based on 46 injuries reported in the children (no repeat injuries to
children) and 1,418 observations in the dataset.

${ }^{2}$ Estimated numbers of injured children per 100 children per year.

is given in Table 5; the analysis is based on 39 farm work injury events for 1,028 observations for all children in the study. Male gender was a significant factor $(\mathrm{OR}=3.77 ; 95 \%$ CI: 1.63-8.75) for the risk of farm injury. Children aged 16-18 years were $40 \%$ more likely to experience a farm work injury than other age groups. Working more than 180 days per year, performing farm work independently, and working on a beef cattle farm (compared to other commodity farm) increased the risk for a farm work injury, although none of these associations were statistically significant. There was a significant elevation in the farm injury rate in the first follow- 
Table 5. All children: GEE analysis of predictors of farm work injuries ( $\mathrm{N}=46$ injury events) in the cohort from the baseline, first and second follow-up surveys

\begin{tabular}{llll}
\hline Risk factor & $\begin{array}{c}\text { Estimated } \\
\text { Odds Ratio }\end{array}$ & $95 \% \mathrm{Cl}$ & P value \\
\hline Gender: & & & \\
\hline Male & 3.77 & $1.63-8.75$ & .002 \\
\hline Female & 1.00 & & \\
\hline Age (years): & & & \\
\hline 16-18 & 1.40 & $0.54-3.60$ & 0.48 \\
\hline 10-15 & 0.93 & $0.36-2.41$ & 0.88 \\
\hline 5-9 & 1.00 & & \\
\hline Farm work in past 12 months (days): & & & \\
\hline Half or more days (>=180) & 1.59 & $0.74-3.41$ & 0.23 \\
\hline Less than half days (<180) & 1.00 & & \\
\hline Level of involvement in farm work: & & & \\
\hline Performing tasks independently & 1.78 & $0.89-3.57$ & 0.104 \\
\hline Working under supervision or assisting & 1.00 & & \\
\hline Type of farm: & & & \\
\hline Beef cattle farm & 1.40 & $0.73-2.69$ & 0.31 \\
\hline Other farm & 1.00 & & \\
\hline Time period: & & & \\
\hline Follow-up (2001) & & & \\
\hline Follow-up (2000) & & & \\
\hline Baseline & & & \\
\hline
\end{tabular}

up survey (summer 2000), which may have been partially related to the collection of data during the typically busy summer months in which children work more hours and which has been demonstrated to be a period of increased rates of injury. The results from the analysis for male children only (Tab. 6), based on 32 male children who experienced

Table 6. Male children. GEE analysis of predictors of farm work injuries ( $\mathrm{N}=39$ injury events) in the cohort from the baseline, first and second follow-up surveys

\begin{tabular}{llll}
\hline Risk factor & $\begin{array}{c}\text { Estimated } \\
\text { Odds Ratio }\end{array}$ & $95 \% \mathrm{Cl}$ & P value \\
\hline Age (years): & 1.51 & $0.53-4.36$ & 0.44 \\
\hline $16-18$ & 0.86 & $0.29-2.53$ & 0.79 \\
\hline $10-15$ & 1.00 & & \\
\hline 5-9 & & & \\
\hline Farm work in past 12 months (days): & 1.18 & $0.52-2.67$ & 0.70 \\
\hline Half or more days (>= 180) & 1.00 & & \\
\hline Less than half days (<180) & & & \\
\hline Level of involvement in farm work: & 2.41 & $1.15-5.06$ & 0.02 \\
\hline Performing tasks independently & 1.00 & & \\
\hline Working under supervision or assisting & & & \\
\hline Type of farm: & 1.32 & $0.65-2.70$ & 0.45 \\
\hline Beef cattle farm & 1.00 & & \\
\hline Other farm & & & \\
\hline Time period: & & & \\
\hline Follow-up 2 & & & \\
\hline Follow-up 1 & & & \\
\hline Baseline & & & \\
\hline
\end{tabular}

farm injuries, found that the level of involvement in farm work (performance of tasks independently) was a significant predictor of injury risk, with independent work associated with a 2.4-fold increased risk $(\mathrm{OR}=2.41$; 95\% CI: 1.15-5.06, $\mathrm{P}=0.02$ ) for a farm work injury, after controlling for days of working, age, period of data collection, and commodity type of the farm.

\section{DISCUSSION}

The results of this three-year cohort study of children aged $5-18$ years living on family farms in Kentucky documents the high proportion who undertake farm work and farm chores. Overall, an estimated $70-80 \%$ of children are involved in animal-related chores, with the care and feeding of cattle being one of the primary tasks. While there were evident age- and gender-related patterns to the tasks performed, it is apparent that farms with cattle are more labour-intensive for children, especially for males in the age range of 15-18 years.

This study documents a wide variation in practices regarding the tasks and the levels of participation of children working with family-owned operations in Kentucky. While 15 - 18-year-old boys averaged 19.7 hours of work on beef cattle farms in the summer, the range of work hours extended from one hour to over 42 hours per week. A large proportion of these young males participated in tasks that involved using a tractor or other farm equipment, especially ATVs, to manage the feeding and care operations for beef cattle on the farm. Indeed, for perhaps a third of these boys, involvement in tasks including cattle castration, dehorning, and assisting in the delivery of a calf, was common. Calves are reservoirs for multiple enteric pathogens, including Escherichia coli O157:H7, Cryptosporidium parvum, Giardia, and Brucella [28]. Consequently, children's presence at the birth of a calf puts them at risk for gastrointestinal illness, as well as risk of contracting brucellosis, cryptosporidiosis, Q fever, toxoplasmosis, and other zoonotic illness [29]. The general recommendation is that, given the heightened risk of injury along with illness which may occur from contact with livestock, veterinarians or experienced farmers should assist with calf delivery.

Although animal hazards, such as working with cattle and being in the vicinity of cattle on a farm, have typically ranked high among parental concerns (ranked second, following machinery-related hazards), McKnight et al. documented that prohibitions concerning the proximity of children to animals were few and generally limited to swine [30]. The necessity for accomplishing the required work is critical and parents may allow children to perform high-risk chores when economically pushed, or the available labour supply is inadequate [31].

The overall farm work injury rates for children in this cohort (5.1 injured children per 100 children per year for males and 1.0/100 for females) are comparable to those reported elsewhere $[7,10,14,27,30]$. Adolescent males remain the high risk group for farm work injuries. The cumulative incidence of farm work injuries on beef cattle farms is 3.9 injured children per 100 children per year for those aged 5-18 years. Rivara et al. reported a non-fatal farm injury rate equivalent to 1.7 injuries per 100 children using the CPSC National Electronic Injury Surveillance System, an approach that captures more severe injuries, and consequently, will yield 
a lower rate [32]. In its most current report, the Childhood Agricultural Injury Surveillance system (CAIS) estimated the child agricultural injury rate in 2006 as 1.04 injuries per 100 youth per year [34]. While the presented data indicates that $74 \%$ of the reported farm work injuries in children required medical attention, and $46 \%$ resulted in at least four hours missed from work or school; roughly one-quarter of the farm work injuries noted in the current study would not have been documented in medical records. Consequently, the continuing need for surveillance from non-hospital or clinic sources is needed to understand the agricultural injury burden among children working on farms.

Children living and working on beef cattle farms in Kentucky were at a modest increased risk of a farm work injury (OR=1.40; 95\% CI:0.73-2.69), while controlling for age, gender, level of work involvement, days worked, and the time period of study. Consequently, working on farms with beef cattle increased the risk for a farm work injury among children after controlling for the increased labour requirements (days worked) on these farms. However, the presented data suggest that few of the farm work injuries (less than $8.7 \%$ ) would have resulted from direct contact with cattle on these farms. The majority of the injuries occurred while performing cattle-related tasks, such as feeding, the use of tractors and ATVs, and the use of hand tools and contact with barbed wire.

The level of supervision in the performance of farm chores was an independent risk factor for a farm work injury for male children. Boys who performed farm chores independently were at an increased risk for an injury $(\mathrm{OR}=2.41 ; 95 \% \mathrm{CI}$ : 1.15-5.06), following adjustment for important covariates in the model. Performing tasks independently increased the risk for a farm work injury for all children in the cohort analysis, although the result was not significant. This finding suggests that parents and guardians who have adopted an approach that continues to emphasize the supervision of children's farm chores into adolescence, when chores typically are more often independently performed, report fewer farm work injuries among their children. It is difficult to assess whether this supervision variable is a proxy for other variables that reflect a safer farm environment or the specific tasks assigned to the children. Larson-Bright et al., using data from a regional rural injury study (RRIS-II), found decreased risks of injury for working-aged children with 'moderate' compared to 'very strict' parental monitoring (0.60; 0.40-0.90), and with parents believing in the importance of physical $(0.80$; $0.60-0.95)$ and cognitive readiness $(0.70,0.50-0.90)$ when assigning new tasks [34].

This study was premised on state-wide surveillance data which extended the collection of data across time. This cohort design provides a better approach to examining the temporal relationships between selected risk factors (e.g., level of supervision and type of farm) and work-related injuries. The recall of injury events by proxy respondents, particularly minor injuries, may have resulted in the modestly higher injury rates reported in the current study. The temporal relationships between days of work, level of supervision, type of farm and the associated farm work injuries examined in the presented model, are clearly accounted for using the longitudinal design and the GEE approach to account for the time-dependent exposures and the correlated nature of the data. The study did allow for the control of exposure time (days of work in the past year) in the repeated measures of farm work injuries among the children, suggesting that both independent farm chore performance and beef cattle farms may increase the risk for injury, after adjustment for time worked.The overall response rates for the telephone surveys were acceptable, given the often difficult task of achieving participation from rural cohorts.

While the longitudinal cohort design is potentially a powerful one with respect to the temporal assessment of relevant risk factors, the relatively small number of farm work injury events in the children's cohort $(\mathrm{N}=46)$ limited the number of risk factors that could be examined in the workrelated injury analysis. In addition, the use of a fixed cohort of children constrained the possibility of examining the injury experience among the very young children. The limitations in using self-reported farm injury data for children have been well-documented in several studies $[10,18,24]$. The loss to follow-up was a concern of this design; the largest component of this loss in a cohort study of children was due to the aging of the cohort, given the eligibility criteria, as opposed to a lack of participation in the data collection efforts. Response bias was not apparent by age or gender groups; however, the data indicate that higher income farms are more likely to continue participation across the several surveys in the study.

\section{CONCLUSIONS}

With an estimated one-and-a-half million children living on farms and ranches, especially in rural States, they compose a work force that is important to the family farm. Although they work fewer hours per week, in some studies, data indicate that when adjusted for actual work exposure time, adolescent injury rates on agricultural establishments surpass those of adults. While recent national data on trends in children's agricultural injuries indicate a decline, the contribution of children to the labour force on farms will be continually influenced by economic considerations, such as labour supply and commodity prices. The wide variation in hours worked, and in diversity of tasks performed on the farm, complicates the development of effective injury interventions and thus necessitates the need for a multifaceted approach to the prevention of farm injuries to children and adolescents.

Environmental modifications of the work environment tend to be among the most effective measures for the control of agricultural injuries. Structuring the tasks related to animal care and feeding operations may have the biggest impact on reducing the risk of injuries to children on animal intensive operations. Farm management practices, which include pasturing cattle and using professional veterinary services for the selected tasks, may be among the approaches for reducing risk to children working on cattle farms. The formulation of age and developmentally appropriate guidelines for children who work specifically for beef cattle and livestock farms, would complement the North American Guidelines for Children's Agricultural Tasks [35]. Studies such as those conducted in the Midwest on management intensive grazing operations, document the reductions in children's exposure to farm machinery; however, there may be consequent increases in their direct contact with cattle. An appreciation of the trade-offs in risk is required. The role of injury prevention research is to allow for a child's continued, developmentally appropriate participation in farm work, while identifying the important risk factors. This 
study suggests that an additional focus on the role of parental supervision, perhaps especially on farms in which children work with large animals, is one avenue for continued effort, along with environmental modifications in the manner in which feeding and care operations are undertaken.

\section{Acknowledgements}

This study was funded by the Southeast Center for Agricultural Health and Injury Prevention (NIOSH Grant No. 1 R01 OHO3924-01). The authors wish to thank Dr. Ron Langley and the staff at the Survey Research Center at the University of Kentucky for their assistance in implementing the study. The editorial assistance of Dr. Wayne Sanderson and Teresa Donovan at the Southeast Center for Agricultural Health and Injury Prevention is also appreciated. The authors also extend their thanks to the Kentucky farmers and their families from the original Farm Family Health and Hazard Surveillance Project in Kentucky. Without their support, this study would not have been possible, and it is hoped that the results may provide some benefit as they continue their important work on the family farms of Kentucky.

\section{REFERENCES}

1. Reed DB, Claunch DT. Nonfatal farm injury incidence and disability to children: a systematic review. Am J Prev Med. 2000; 18(4 Suppl): 70-9.

2. McCurdy SA, Carroll DJ. Agricultural injury. Am J Ind Med. 2000; 38(4): 463-80.

3. Forst L, Erskine T. Farm injuries in Ohio, 2003-2006: a report from the emergency medical services prehospital database. J Agric Saf Health. $2009 ; 15(2): 171-83$.

4. Lewandowski B, Szymanska J. Agriculture-related severe craniofacial injuries in rural children and adolescents. Ann Agric Environ Med. 2008; 15(1): 59-62.

5. Paulson EH, Gerberich SG, Alexander BH, Ryan A, Renier CM, Zhang $\mathrm{X}$, et al. Fall-related injuries among agricultural household members: Regional Rural Injury Study II (RRIS-II). J Occup Environ Med. 2006; 48(9): 959-68.

6. Hendricks KJ, Adekoya N. Non-fatal animal related injuries to youth occurring on farms in the United States, 1998. Inj Prev. 2001; 7(4): 307-11.

7. Hendricks KJ, Hendricks SA. Changing farm injury trends by sex for youth living on US farms, 1998-2006. J Rural Health. 2010; (2): 182-8.

8. Brison R, Pickett C. Nonfatal injuries in 177 eastern Ontario beef and dairy farms: a one-year study. Am J Ind Med. 1992; 21: 623-36.

9. Cleary J, Benzmiller J, Kloppedal E, Gallagher D, Evans A. Farm injuries in Dane County, Wisconsin: an epidemiological study. Arch Environ Health. 1961; 3: 201-8.

10. Gerberich SG, Gibson RW, French LR, Renier CM, Lee TY, Carr WP, et al. Injuries among children and youth in farm households: Regional Rural Injury Study-I. Inj Prev. 2001; 7(2): 117-22.

11. Hoskin AF, Miller TA. Farm Accident Surveys: A 21 state summary with emphasis on animal-related injuries. J Safety Res. 1979; 11(1): 2-13

12. Pratt D, Marvel L, Darrow D, Stallones L, May J, Jenkin P. The dangers of dairy farming: the experience of 600 workers followed for two years. Am J Ind Med. 1992; 21: 637-50.
13. Erkal S, Gerberich SG, Ryan AD, Alexander BH, Renier CM. Horserelated injuries among agricultural household members: Regional Rural Injury Study II (RRIS-II). J Rural Health. 2009; 25(4): 420-7.

14. Erkal S, Gerberich SG, Ryan AD, Renier CM, Alexander BH. Animalrelated injuries: a population-based study of a five-state region in the upper Midwest: Regional Rural Injury Study II. J Safety Res. 2008; 39(4): 351-63.

15. Nordstrom D, Layde P, Olson K, Stueland D, Brand L, Follen M. Incidence of farm-work-related acute injury in a defined population. Am J Ind Med. 1995; 28: 551-4.

16. Layde P, Nordstrom D, Stueland D, Wittman L, Follen M, Olson K. Animal-related Occupational injuries in farm residents. J Agric Saf Health. 1996; 2(1): 27-37.

17. Waller JA. Injuries to farmers and farm families in a dairy state. J Occup Med. 1992 Apr; 34(4): 414-21.

18. Browning S, Truszczynska H, Reed D, McKnight R. Agricultural injuries among older Kentucky farmers: results from the farm family health and hazard surveillance study. Am J Ind Med. 1998.

19. Boyle D, Gerberich S, Gibson R, Maldonado G, Robinson R, Martin F, et al. Injury from dairy cattle activities. Epidemiology. 1996; 8(1): 37-41.

20. Fisher RM, Berg RL, Marlenga B. Children's exposures to farm worksite hazards on management-intensive grazing operations. J Agromed. 2009; 14(2): 192-7.

21. Morrongiello BA, Pickett W, Berg RL, Linneman JG, Brison RJ, Marlenga B. Adult supervision and pediatric injuries in the agricultural worksite. Accident, Analysis and Prevention. 2008; 40(3): 1149-56.

22. Marlenga B, Brison RJ, Berg RL, Zentner J, Linneman J, Pickett W. Evaluation of the North American guidelines for children's agricultural tasks using a case series of injuries. Inj Prev. 2004; 10(6): 350-7.

23. Marlenga B, Pickett W, Berg RL. Agricultural work activities reported for children and youth on 498 North American farms. J Agric Saf Health. 2001; 7(4): 241-52.

24. Browning SR, Westneat SC, Donnelly C, Reed D. Agricultural tasks and injuries among Kentucky farm children: results of the farm family health and hazard surveillance project. Southern Med J. 2003; 96(12): 1203-12.

25. National Agricultural Statistics Service. Census of Agriculture 1997. Washington, DC: United States Department of Agriculture (USDA); 1997.

26. SAS Institute. SAS/STAT user's guide. 6th edition. Cary: SAS Institute, Inc.; 2010.

27. Twisk JWR, Smidt N, Vente W. Applied analysis of recurrent events: a practical overview. J Epidemiol Comm Health. 2005; 59(8): 706-710.

28. Smith KE, Stenzel SA, Bender JB, et al. Outbreaks of enteric infections caused by multiple pathogens associated with calves at a farm day camp. Pediatric Infect Dis J. 2004; 23(12): 1098-1104.

29. Miron D, Kenes J, Dagon R. Calves as a source of an outbreak of cryptosporidiosis among young children in an agricultural closed community. Pediatric Infect Dis J. 1991; 10(6): 438-440.

30. McKnight RH, Piercy LR, Townley KF, Kidd PS, Cole HP. Parents' concern for children's farm safety. Texas J Rural Health. 1995; 14: 10-19.

31. Kidd P, Townley K, Cole H, McKnight R, Piercy L. The process of chore teaching: implications for farm youth injury. Fam Comm Health. 1997; 19(4): $78-89$.

32. Rivara FP. Fatal and non-fatal farm injuries to children and adolescents in the United States, 1990-3. Inj Prev. 1997; 3(3): 190-4.

33. Hendricks KJ, Goldcamp EM. Injury surveillance for youth on farms in the U.S., 2006 J Agric Saf Health. 2010; 16(4): 279-91.

34. Larson-Bright M, Gerberich SG, Masten AS, Alexander BH, Gurney JG, Church TR, et al. Parents' safety beliefs and childhood agricultural injury. Am J Ind Med. 2009; 52(9): 724-33.

35. Lee B, Marlenga B, editors. Professional Research Manual:North American Guidelines for Children's Agricultural Tasks. Marshfield, WI: Marshfield Clinic. 1999. 